\title{
How Formative Assessments Drive Instructional Decision Making in the Classroom
}

\author{
Dr. Whitney Perro \\ Walden University \\ 100 S Washington Ave \#900 \\ Minneapolis, MN 55401, United States \\ Dr. Anissa Harris \\ Senior Contributing Faculty \\ Walden University \\ $100 \mathrm{~S}$ Washington Ave \#900 \\ Minneapolis, MN 55401, United States \\ Dr. Sunddip Panesar- Aguilar (Corresponding Author) \\ University of St. Augustine \\ 1 University Blvd, St. Augustine, Florida \\ United States
}

\begin{abstract}
The purpose of this qualitative case study was to better understand the formative assessment processes that drive instructional decision making. The conceptual framework by Chappuis and influenced by Black and Wiliam includes the strategic process for successful formative assessment teaching and learning. The research questions explored the use of homework as a formative assessment in classrooms. Data collection included face- to-face interviews with 10 general education Grade 3-5 teachers in two different schools; a 2-week document analysis of homework assigned in language arts and mathematics; and a focus group of participants. The themes that emerged from the coded data identified ineffective teacher use of feedback, self-assessment, and learning targets-essential practices of the formative assessment process. Improving the formative assessment process for teaching and learning may encourage positive social change through promoting teacher self-efficacy and collaboration through a professional development paired with a professional learning community.
\end{abstract}

Keywords: formative assessment, student homework, assessments, instructional practice, summative assessment.

\section{Introduction}

During the school year, teachers have opportunities to assess student learning and to use this evidence to adjust instruction. It is important to align the different assessments teachers use to guide instruction. Formative assessments provide feedback teachers and students use during the course of instruction (Hattie, Fisher, \& Frey, 2016). This type of assessment differs from summative assessments that occur after an instructional unit and require a decision that learning occurred (Clark, 2012). The seminal work of Black and Wiliam (1998) broadly defined assessment to include all activities that gather diagnostic information to change teaching and learning. Modern researchers such as Adesope, Trevisan, and Sundararajan (2017) and Metcalfe (2017) still use the same definition. Under this definition, formative assessment includes many aspects of classroom activities. Some of the activities include observation, discussions, and analysis of homework and tests. Assessments are considered formative when the data collected is then used to adjust instruction and learning. These adjustments are intended to meet student needs more completely (Dixson \& Worrell, 2016).

\subsection{Problem}

This study was an exploration of the misalignment between formative and summative assessment at the local school, in an effort to align instruction, assessment, and student outcomes. At the local school, the problem was that the process for developing homework to formatively assess student learning did not appropriately align with the student outcomes required by the higher-level summative assessments given in the classroom and on standardized tests. At the local setting, a school self-study revealed that homework assignments appeared to be at lower levels of Bloom's taxonomy and failed to adequately prepare students to perform at the application and critical thinking levels of Bloom's taxonomy (Bloom, 1956). 
Student homework required identification of terms, definitions, and content knowledge, but did not prepare students to perform the more complex critical thinking problem solving items on summative assessments. There was a gap in practice as to the expected student cognition to complete homework and perform proficiently on summative assessments.

\subsection{Purpose}

The purpose of this qualitative intrinsic case study was to better understand the processes Grade 3-5 teachers use to develop homework to formatively assess student learning outcomes. Formative assessments can have a truly transformative effect on the classroom environment (Black \&Wiliam, 2010). Through proper application, teachers may become more effective, students may become actively engaged, and they both may become intentional learners.

\subsection{Guiding Research Questions}

Through this case study research, elementary teachers in Grades 3-5 shared their processes for developing homework to formatively and summatively assess student learning outcomes. Despite the district homework policy for elementary teachers, there remained a gap in practice relative to the expected level of student cognition required to complete homework and to perform proficiently on summative assessments. To better understand the current processes for developing homework that properly aligned with both formative and summative assessments practices in two local elementary schools, the central research question was:

RQ: How do elementary teachers in Grades 3-5 incorporate formative assessment strategies with homework to prepare students for summative assessments?

In order to provide a broader view of this study, three subquestions were included:

SRQ1: How do teachers prepare, select, or create formative assessments in their

classrooms?

SRQ2: How do teachers use data from formative assessments to prepare instruction?

SRQ3: How does homework align with summative assessments?

\subsection{Conceptual Framework}

This study was guided by the formative assessment theory postulated by the seminal work of Black and Wiliam (1998; 2006) and articulated by Chappuis (2005) into a strategic process framework. In an effort to guide educators through the best practices to appropriately apply formative assessment in classroom instruction, Chappuis articulated three key questions that framed the analysis in this study:

- Where am I going?

- Where am I now?

- How can I close the gap?

In order to effectively answer these key questions, Chappuis (2005) developed a systematic formative assessment process with seven specific strategies for teachers:

- Strategy 1: Provide a clear and understandable vision of the learning target.

- Strategy 2: Use examples of strong and weak work.

- Strategy 3: Offer regular descriptive feedback.

- Strategy 4: Teach students to self-assess and set goals.

- Strategy 5: Design lessons to focus on one aspect of quality at a time.

- Strategy 6: Teach students focused revision.

- Strategy 7: Engage students in self-reflection and let them document and share their learning. (pp. 40-43)

Tracing the instructional decision-making processes of teachers responding to these three key questions and application of these seven strategies revealed insight regarding the local teachers' use of best practices relative to formative assessment in the classroom. Therefore, the application of the key questions and strategies for best formative assessment practice were embedded throughout this study. In order to support the veracity and research-base of Chappuis's framework, it is important to understand its seminal underpinnings.

\subsection{Pertinent Literature}

Chappuis's framework also is rooted in seminal research, as well as relevance to the problem and approach in this study. As shown in Table 1, Chappuis's (2005) formative assessment framework, the three key questions as well as the seven strategies for effective formative assessment, all align with the best practices researched by Black and Wiliam $(1998,2006,2009)$.The development and analysis processes in this study follow Chappuis's (2005) theoretical model for effective instructional implementation of formative assessment practices. 
Table 1.

Comparison of Chappuis's and Black and Wiliam's Formative Assessment Characteristics with Three Key Questions

\begin{tabular}{|c|c|c|}
\hline Key questions & Chappuis's formative assessment strategies & $\begin{array}{l}\text { Black \&Wiliams' formative assessment } \\
\text { characteristics }\end{array}$ \\
\hline $\begin{array}{l}\text { Where am I } \\
\text { going? }\end{array}$ & $\begin{array}{l}\text { 1. Provide a clear and understandable vision of } \\
\text { the learning target. }\end{array}$ & 1. Action to close the learning gap \\
\hline \multirow{3}{*}{$\begin{array}{l}\text { Where am I } \\
\text { now? }\end{array}$} & Use examples of strong and weak work. & Peer assessment \\
\hline & Offer regular descriptive feedback. & Feedback quality \\
\hline & & $\begin{array}{l}\text { 4. Discourse between learner and } \\
\text { teacher }\end{array}$ \\
\hline \multirow[t]{10}{*}{$\begin{array}{l}\text { How can I close } \\
\text { the gap? }\end{array}$} & Teach students to self-assess and set goals. & $\begin{array}{l}\text { 5. Students self-assess during the } \\
\text { learning process }\end{array}$ \\
\hline & & $\begin{array}{l}\text { 6. Students create with assistance } \\
\text { from teacher process goals }\end{array}$ \\
\hline & Design lessons to focus on one aspect of & Choice of task by learner \\
\hline & quality at a time. & High quality questions \\
\hline & & Mastery learning \\
\hline & Teach students focused revision. & Frequent assessments \\
\hline & & Student formulation of strategies \\
\hline & 7. Engage students in self-reflection and let & Perception by learner of the gap \\
\hline & them document and share their learning. & $\begin{array}{l}\text { 13. Self-perception of the learner's } \\
\text { effort and ability }\end{array}$ \\
\hline & & Task motivation \\
\hline
\end{tabular}

As noted by Chappuis (2005), there are four essential components in the formative assessment process: (a) learning targets, (b) feedback, (c) self-assessment, and (d) specific steps to improve. Each element must be in place to have an effective formative assessment practice that is useful for improving teaching and learning. Understanding the components for effective formative assessment is essential in the analysis of instruction and learning.

Learning targets. The first essential element in the formative assessment practice is the articulation of and path to clear learning targets. Teachers must be clear on what they want the students to learn (Brookhart, 2017; Mandinach\& Gummer, 2013). For example, if the students were asked to use vivid vocabulary, the formative assessment should require the vivid vocabulary. The students have evidence based on criteria to see how their work compares to the objective. The students understand what they do well and where they could improve with clear learning targets. A learning target is more than just noting the objective on the board; it helps students and teachers monitor the learning process. Students, however, must understand what the targets mean. Assignments must align with the learning target, as this alignment is where the target is translated into action. The learning target is the initial step in the formative assessment practice.

Feedback. Feedback is another essential element of formative assessments. Feedback is the teacher's intentional response to student work to improve learning (Clark, 2015). Feedback can be written, oral, or demonstrated. Using feedback provides opportunities for students to grow by giving them knowledge of their work that they might not understand on their own (Brookhart, 2016; Clark, 2015). Feedback provides the students information on what to do next. The use of feedback relies on two elements to successfully improve learning. For example, if the class was asked to complete a mathematical story problem involving dividing and then multiplying to find a total cost; feedback on a formative assessment might include where to place the decimal point. This type of feedback is different from a summative assessment that the teacher might just mark as correct or incorrect. The first part of feedback is for teachers to interpret the evidence from student work against the set criteria or rubric. The second part of feedback is informing the student what should come next towards the learning target (Brookhart, 2016).

Feedback can build on strengths and improve weaknesses. Feedback enhances cognitive processing (Brookhart, 2016). These strengths and weaknesses transfer to students setting learning goals.

Self-assessment. Self-assessment encourages learners to take control of their learning by allowing them to target their learning and help gather information along the way to see how they are doing. Self-assessment activates students as the owners of their learning (Forster \& Souvignier, 2014). It is a form of feedback to oneself. 
This information on what to do next guides the students in answering the question How can I close the gap? For instance, a student receives feedback about using vivid language. The student would then self-assess to determine if at least five examples of vivid language are included in upcoming assignments. It is the continuous process of how to learn. The clear targets and the feedback moved students towards self-assessment and achieving the desired outcomes. In addition, specific steps to improve in formative assessments must also be well developed.

Specific steps to improve. The final component of the formative assessment process is providing the students with specific steps to improve (Chappuis, 2005). This includes the types of questions teachers ask. Teachers should use formative assessments to ask higher-order questions to ascertain if learners are understanding the content, and not just recalling the concepts. Strategic teacher questioning through formative assessments scaffolds learners as they move from thin or passive understandings; to a deeper conceptual change (Clark, 2015). Despite professional development and training, teachers' questions lack quality and rigor, as they are frequently low-level and quickly asked recall questions (Brookhart, 2017; Mikhwanazi et al., 2014). These types of questions lessen student engagement. Teachers must specifically plan for strategic questions that are connected to the learning targets. These questions require students to think beyond factual recall. Questions that require thinking about a learning target as opposed to right/wrong answers help students show evidence of learning (Brookhart, 2016). One example would be instead of asking what is the capital of Pennsylvania, ask the students to think of the state and why the founders chose to locate the capital in Harrisburg. The students think about their prior knowledge to create new understandings. However, the teachers cannot be the only ones asking questions. In the formative assessment process, students are encouraged to contemplate and ask meaningful questions. Through inquiry, students can construct their understanding.

\section{Methodology}

The purpose of this qualitative intrinsic case study was to better understand the current processes in the local district for developing homework that properly aligns with both formative and summative assessment practices. The research design logically derived from the research question to understand teacher practices related to using homework as a formative assessment. The selected research design that best aligned with the purpose of the study, conceptual framework, and the central research question was a qualitative case study with an intrinsic or exploratory focus (Creswell, 2013).Because there is a lack of research in the area of homework as a formative assessment, an intrinsic case study allowed a comprehensive understanding of how elementary teachers use homework as a formative assessment to prepare students for higher level summative assessments. For this study, the case was elementary teachers and the context was the school or classroom. An intrinsic case study highlighted the uniqueness of this setting as the case was bounded by a specific place, the two elementary schools. Case study illustrates a unique case that was described and detailed. Yin (2014) noted data are analyzed in the context of its use in an intrinsic case study. In this study, the data collected from the elementary teachers in a suburban district were analyzed to determine ifhomework was being used formatively to prepare students for higher level summative assessments.

\subsection{Participants and Sampling}

The study occurred in a suburban district located in Northeastern New Jersey. The district has two elementary schools, a middle school, and one high school. The sites for the study were the two district elementary schools that each educates children in Grades K-5. One of the elementary schools receives Title 1 funding and has 50 teachers, while the other does not receive this federal funding and has 47 teachers. Grades 3-5 was targeted in this study.In 2017, each grade level had approximately 80 students at each building for a total of 160 students in each grade level for the district. A purposeful sample consisting of Grades 3-5 teachers who assign homework provided understanding, insight, and information-rich data for this study (Creswell, 2013).Key informants are participants having specific knowledge of the investigated topic (Yin, 2014). The participants in this study were selected from the two participating elementary schools in the local district. To be included in this study, a prospective participant must have met the following criteria:

- be a general education teacher in Grades 3-5 at one of the elementary schools in the district, and

- assign homework as part of classroom instruction and assessment processes.

\subsection{Data Collection}

Data were collected through personal interviews, a focus group, and a document review. Data collection procedures using systemic steps were followed (Yin, 2014).

The interviews and focus group data generated themes from the participants' personal formative assessment practices. The document review added depth to the study and triangulation of data. The goal of the data collection was to gain rich, thick, in-depth information from the participants. A matrix was used to provide evidence of how each collection tool/item aligned with the research questions and literature for this study. The data collection phase lasted approximately 5 weeks. 


\section{Data Analysis}

Data coding was completed two weeks after the final interview and the focus group. The entire process of coding and data analysis took four weeks. Open and axial coding was applied to all data gathered. The coding process identified common themes and categories. Open coding. Open coding involves looking for distinct concepts and categories within the data. The benefit of open coding is that concepts are developed from the raw data and can be grouped into conceptual categories. Open coding builds a descriptive framework for later analysis (Creswell, 2013). After transcription of the interviews and focus group sessions, the first stage of coding began. the data was reviewed several times in order to create tentative labels and to summarize what was occurring. The text data was highlighted and marked, indicating concepts related to the research question. Different colored highlighters distinguished broad concepts and categories. For example, if teachers consistently discussed grading homework, the same color highlight was used. Feedback on homework became a concept. The highlighted codes were identified for further analysis. Predetermined codes were not used. The text to define concepts and categories was primarily the focus.

Axial coding. Axial coding is the process of relating categories. In axial coding, the concepts and categories defined in open coding were explored as to how they are related. Axial coding is a more selective approach to looking at the data. This step is considered a cyclical act of linking data to ideas and ideas back to data (Creswell, 2013). Patterns within the coded data was checked. the text was re-read and reviewed in order to identify text that supported the concepts and categories established in the open coding process. The significant coded statements were sorted and grouped into larger categories which were interpreted as themes or patterns. Coding the responses into themes organized and gave meaning to the data collected. Connections among the categories discovered in the open coding was reviewed. A spreadsheet and reflective notes was used to make comparisons between the responses, in order to build concepts and generalizations. Themes are an outcome of coding (Yin, 2014).

\section{Findings}

Analysis involves using the data to describe the phenomenon. Yin (2014) described this final stage, focus of analysis, with attention to detail, increasing clarity and providing rigor. The themes for analysis were drawn from the research questions, interview, and focus group questions and were supported by the literature review. During the course of interviews, other themes developed. These themes were used to look for patterns and relationships. It was also important to revisit the data and to review and revise coding. During this stage, a determination was made to ensure the findings made sense, were credible to the participants, and if any conclusions were transferable and able to be generalized. Continual refinement occurred during this final stage. The codes were gradually combined and reduced. Any overlap of codes was eliminated; this provided a clearer view of the patterns or themes. The themes were typically big ideas that indicated what was learned in the study (Creswell, 2013). The findings were summarized using narrative and tables. Data were interpreted in this final phase. The process of reviewing the data was repeated until the research questions had been answered and meaning was culled from the data. Saturation occurred when no new codes, categories, or themes were surfacing from the analysis of data. The study was guided by three research questions focused on: (a) creation of formative assessments, (b) using data from formative assessments, and (c) alignment with summative assessments. The findings were organized by each research question and the framework of formative assessments related to each question. The codes represented the pillars of formative assessments. The participants mentioned many assessment strategies used throughout the day and practices in place to document student growth. These became categories and then themes. Teacher quotes were used to support the themes. Through the data collection and analysis, there were significant findings related to the local problem. Data triangulation assisted to corroborate the findings and assured validity. The three methods used to apply triangulation included: (a) interviews, (b) focus group, and (c) a review of documents. Most of the data collected derived from interviews; however, the focus group and review of documents validated the themes identified in the interviews (Creswell, 2012). The focus group and document analysis added validity to the findings from the interviews and added rigor to the study (Yin, 2014).

\section{Interviews}

Through the interviewing process, an overarching finding for this study revealed that teachers did not fully understand the difference between formative and summative assessments. They incorporated attempts at formative assessmentsbut could not name what they were doing with the information. For example, during the day, teachers discussed collecting data regarding student progress through Do Nows and Exit Tickets. This appeared to be a standard practice in the two elementary schools for collecting formative data. Teachers shared that the Do Nows and Exit Tickets implemented provided possible groupings or indicated the need to reteach. Without a full understanding of a formative assessment and the components that compose this assessment, gaps formed in the formative assessment practice at the local level. At the local site the gaps in practice appeared in the areas of feedback, self-assessment, learning targets, and aligning formative and summative assessments. 


\section{Focus Group}

The findings from the focus group indicated the local teachers were not fully implementing the formative assessment process. At the local site, the areas of feedback, learning targets, self-assessment, and aligning formative and summative assessments displayed gaps in practice. Feedback is a key component to the formative process and teachers were not applying specific and constructive feedback. Participants needed to better understand the importance of feedback in the formative assessment cycle and how to provide it. Through an analysis of the data collected during the focus group, it was discovered that teachers not encouraging students to self-assess and truly be part of the learning process. At times, students worked with a peer for editing purposes, or corrected their own homework, but they were not fully self-assessing. Teachers should be aware of the importance of self-assessment and how to support students with this skill. The findings derived from the focus group also indicated teachers did not set learning targets and needed training on how to align the targets with the state standards. Teachers indicated through the focus group responses that they noted objectives on the board on a daily basis. However, the objectives were driven by the state standards and teachers noted they did not always indicate what students should be able to do.

\section{Document Analysis}

Unless all the strategies are in place to answer the questions: Where am I going? Where am I now? and How do I close the gap?, teachers are not fully implementing formative assessment practices. An analysis of classroom activities documented and completed during the day such as mini-lessons and conferencing were one aspect of formative assessments, but not the full formative assessment cycle. The activities during the school day provided students with feedback, but the activities were not connected to self-assessment or learning targets. However, when analyzing the homework documents, the teachers did not apply effective feedback practices. A majority of the homework analyzed showed simple comments like "good job" or merely a check mark to indicate the completed assignment. Feedback needs to be specific, concrete, and promote a change in learning for students. The feedback provided on the homework documents lacked effectiveness. In reviewing the lesson plans, formative assessments were not documented or consistently used by teachers in this study. The documentation consisted of goals created from the standards in lesson plans and broad ways to assess the students. For example, most lesson plans simply stated unit test after a 10-day to 2week period. Not one lesson plan reviewed referred to a formative assessment. The local district did not develop a system for teachers to correctly incorporate formative assessment practices. The findings from this study indicated that Grades 3-5 teachers can improve their formative assessment skills and knowledge. Responding to the findings of this study, professional development workshops were developed to help teachers build their formative assessment knowledge. Findings from the study and a literature review served as the foundation for developing this professional development to address the gap in formative assessment and homework practices. This professional development plan highlights strategies to increase teachers' understanding of the formative assessment process and to apply learning targets, feedback, and student self-assessment when assigning homework. The formative assessment process consists of asking three questions and incorporating seven strategies in a cyclical manner to improve student learning. The themes in the study determined the activities and the four intended outcomes. The professional development model incorporated these activities and outcomes.

\section{Findings and Conclusions}

The findings of this study showed the gaps in practice effectively using formative assessment practices when assigning homework in Grades 3-5. 10 teachers were interviewed and participated in a focus group for this study. The interview questions were open-ended and semi-structured. The structure of the focus group also allowed for teachers to respond electronically to belief statements. Additionally, the participants' lesson plans and homework assignments were analyzed. The goal of this data collection was to better understand the processes Grades 3-5 teachers used for developing homework to formatively and summatively assess student learning outcomes. The problem that initiated this study was that the process for developing homework to formatively assess student learning did not appropriately align with the student outcomes required by the higher-level summative assessments given in the classroom and on standardized tests. Data collection was based on the research question: How do elementary teachers in Grades 3-5 incorporate formative assessment strategies with homework to prepare students for summative assessments? As data was collected, it became apparent that teachers did not fully understand or differentiate between formative and summative assessments.

It was also discovered that teachers were not consistently incorporating the formative assessment practices when assigning homework. The professional development created from this study paired with a PLC has the potential to change assessment practices of elementary teachers. This research study was created so teachers could better understand the formative assessment model and how this model could improve student learning. By using professional development and PLCs, schools may improve practices and increase student achievement. 
This research is significant as it reveals teachers' perceptions of using formative assessment practices to create homework assignments. The results of this study contribute to the growing body of research by addressing gaps in practice at the local district.

\section{References}

Adesope, O. O., Trevisan, D. A., \& Sundararajan, N. (2017). Rethinking the use of tests: A meta-analysis of practice testing. Review of Educational Research, 80, 207-245. doi:10.3102/0034654316689306

Black, P., \&Wiliam, D. (1998). Assessment and classroom learning. Assessment in Education, 5(1), 7-74. doi:10.1080/0969595980050102

Black, P., \&Wiliam, D. (2006). Developing a theory of formative assessment. In J. Gardner (Ed.), Assessment and Learning (pp. 295-324). London, United Kingdom: Sage Publications.

Black, P., \&Wiliam, D. (2009). Developing the theory of formative assessment. Educational Assessment, Evaluation and Accountability, 1(1), 15-37. doi:10.1007/s11092-008-9068-5

Black, P., \&Wiliam, D. (2010). Inside the black box: Raising standards through classroom assessment. Kappan Classic, 92(1), 81-90.

Bloom, B. S. (1956). Taxonomy of educational objectives: The classification of educational goals. Handbook 1: Cognitive domain. New York, NY: Longman

Brookhart, S. M. (2013). How to create and use rubrics for formative assessment and grading. Alexandria, VA: ASCD.

Brookhart, S. M. (2016). How to make decisions with different kinds of student assessment data. Alexandria, VA: ASCD.

Brookhart, S. M. (2017). How to use grading to improve learning. Alexandria, VA: ASCD.

Chappuis, J. (2005). Helping students understand assessment. Educational Leadership, 63(3), 39-43.

Clark, I. (2012). Formative assessment: A systematic and artistic process of instruction for supporting school and lifelong learning. Canadian Journal of Education, 35(2), 24-40.

Clark, I. (2015). Formative assessment: Translating high-level curriculum principles into classroom practices. Curriculum Journal, 26(1), 91-114. doi:10.1080/09585176.2014.990911

Creswell, J. W. (2013). Qualitative inquiry \& research design: Choosing among five approaches. Thousand Oaks, CA: Sage Publications.

Dixson, D. D., \& Worrell, F. C. (2016). Formative and summative assessment in the classroom. Theory into Practice, 55(2), 153-159. doi:10.1080/00405841.2016.1148989

Forster, N., \&Souvignier, E. (2014). Learning progress assessment and goal setting: On reading achievement, reading motivation and reading self-concept. Learning and Instruction, 32, 91-100. doi:10.1016/j.learninginstruc.2014.02.002

Hattie, J., Fischer, D., \& Frey, N. (2016). Do they hear you? Educational Leadership, 73(7), 16-21.

Hawe, E., \& Dixon, H. (2017). Assessment for learning: A catalyst for student self-regulation. Assessment \& Evaluation in Higher Education, 42(8), 1181-1192. doi:10.1080/02602938.2016.1236360

Mandinach, E. B., \& Gummer, E. S. (2013). A systemic view of implementing data literacy in educator preparation. Educational Researcher, 42(1), 30-37. doi:10.3102.0013189X12459803

Metcalfe, J. (2017). Learning from errors. Annual Review of Psychology, 68(1), 465-489.

Mikhwanazi, H. N., Joubert, I., Phatudi, N. C., \& Fraser, W. J. (2014). Teachers' use of formative assessment for the teaching of reading comprehension in grade 3. Mediterranean Journal of Social Sciences, 5(7), 468-475. doi:10.5901/mjss.2014.v5n7p468

Popham, W. J. (2008). Transformative assessment. Alexandria, VA: ASCD.

Qiau, X., Yu, S., \& Zhang, L. (2018). A review on professional learning communities in mainland China. Educational Management, Administration \& Leadership, 46(5), 713-728. doi:10.1177/1741143217707523

Yin, R. K. (2014). Case study research: Design and methods. Thousand Oaks, CA: Sage Publications. 